\title{
Curcumin induces apoptosis in human lung adenocarcinoma A549 cells through a reactive oxygen species-dependent mitochondrial signaling pathway
}

\author{
QINGYONG CHEN ${ }^{1,2^{*}}$, YANYI WANG ${ }^{3}$, KEDI XU ${ }^{4}$, GUOHUA LU $^{1}$, ZHENG YING $^{2}$, \\ LIJUN WU ${ }^{2}$, JIANWEI ZHAN ${ }^{2}$, RUI FANG ${ }^{2}$, YUQUAN WU ${ }^{2}$ and JIANYING ZHOU ${ }^{1 *}$ \\ ${ }^{1}$ Department of Respiratory Disease, First Affiliated Hospital, College of Medicine, Zhejiang University, \\ Hangzhou 310003; ${ }^{2}$ Department of Respiratory Disease, The 117th Hospital of PLA, Hangzhou 310013; \\ ${ }^{3}$ College of Life Science, Guizhou University, Guiyang 550025; ${ }^{4}$ Department of Biomedical Engineering,
} Key Laboratory for Biomedical Engineering of Ministry of Education, Zhejiang University, Hangzhou 310029, P.R. China

Received August 13, 2009; Accepted September 17, 2009

\section{DOI: 10.3892/or_00000648}

\begin{abstract}
Several studies have shown that curcumin can induce apoptosis and inhibit growth in human A549 lung adenocarcinoma cells. However, the mechanism is not completely understood yet. The present study was designed to investigate the effects of curcumin on A549 cells to better understand its apoptosis and apoptosis-related factors in vitro. The apoptosis induction, intracellular reactive oxygen species (ROS) and mitochondrial membrane potential (MMP) were examined by confocal fluorescence microscope and flow cytometry. The MAPK protein expression was examined by Western blot analysis. After treatment with curcumin, apoptosis were observed. Curcumin-induced apoptosis was accompanied by an increase of intracellular ROS level and a loss of MMP. In addition, induction of apoptosis was also accompanied by
\end{abstract}

Correspondence to: Dr Qingyong Chen, Department of Respiratory Disease, The 117th Hospital of PLA, Hangzhou 310013, P.R. China E-mail: cqyong117@hotmail.com

Dr Jianying Zhou, Department of Respiratory Disease, First Affiliated Hospital, College of Medicine, Zhejiang University, Hangzhou 310003, P.R. China

E-mail: drzjy@163.com

${ }^{*}$ Contributed equally

Abbreviations: ROS, reactive oxygen species; MMP, mitochondrial membrane potential; ERK, extracellular signal-regulated kinase; JNK, c-Jun N-terminal kinase; JC-1, 5,5',6,6'-tetrachloro-1,1',3,3'tetraethylbenzimidazolylcarbocyanineiodide; DCFH-DA, 2',7'dichlorofluoresceindiacetate; GSH, glutathione; NAC, N-acetylcysteine

Key words: curcumin, apoptosis, reactive oxygen species, mitochondrial membrane potential, MAPK, lung cancer sustained phosphorylation and activation of JNK, p38 and ERK. However, pretreatment with MAPK inhibitors had no effect upon curcumin-induced apoptosis. GSH and NAC, an anti-oxidant agent, blocked the curcumin-induced ROS production, MMP loss and rescued cells from curcumininduced apoptosis. Our results indicated that curcumin induced apoptosis in A549 cells through a reactive oxygen speciesdependent mitochondrial signaling pathway and independent of MAPK signaling pathway.

\section{Introduction}

Lung cancer is a major public health problem worldwide. Despite recent advances in chemotherapy, lung cancer remains incurable. The effectiveness of chemotherapeutic agents is often limited by the side effects of drug treatment. There is a great necessity to discover novel agents with less severe side effects.

Curcumin-[1,7-bis-(4-hydroxy-3-methoxyphenyl)-1,6heptadiene-3,5-dione (diferuloy 1 methane)], a natural and crystalline compound isolated from the plant curcuma longa, has anti-inflammatory, anti-oxidative, anti-mutagenic and anticarcinogenic properties (1). Our recent and other studies have shown that curcumin can induce apoptosis and inhibit growth in human A549 lung adenocarcinoma cells (2-4). However, the mechanism is not completely understood yet. Some studies have indicated that curcumin exhibits both antioxidant and pro-oxidantive properties. For instance, curcumin at concentrations ranging between 3 and $30 \mu \mathrm{M}$ was able to induce reactive oxygen species (ROS) production in some tumor cells and to a lesser extent in normal human cells (7). Anti-oxidants including glutathione (GSH) and Nacetylcysteine (NAC) significantly reduced curcumininduced ROS generation $(5,6)$. The pro-oxidative effect of curcumin was observed in another study where curcumin at low concentrations reduced ROS formation in human myeloid leukemia cells and Hepatoma G2 cells, but elevated ROS levels at higher concentrations $(7,8)$. In contrast, curcumin, as an anti-oxidant, inhibits ROS formation and apoptosis in human Hepatoma G2 cells and Chang liver cells 
$(9,10)$. However, the precise signaling pathways for the ROS-mediated mitochondrial apoptotic cell death triggered by curcumin still remains unclear, especially in lung cancer cells.

Some studies have shown that both endogenously produced and exogenously added ROS can regulate the activity of mitogen-activated protein kinase (MAPK) pathways that may be involved in cellular responses including proliferation, differentiation and apoptosis $(11,12)$. MAPKs include three major kinases: extracellular signal-regulated kinase (ERK), p38 kinase and c-Jun N-terminal kinase (JNK). Accumulating evidence suggests that curcumin can interact selectively within MAPK signaling cascades (13-15). However, the role of MAPK in the response of curcumin to A549 cells is not clear.

In this investigation, we used the human A549 non-small cell lung cancer cell line as a model to examine the molecular mechanisms of the effect of curcumin on the induction of apoptosis. The new data resulting from these studies indicate that ROS generation and MMP decrease are the early and necessary events for the initiation of curcumin-induced apoptotic signaling. These findings should help to elucidate the mechanisms underlying curcumin-induced apoptosis and provide a basis for the therapeutic use of this compound alone or in combination with other chemotherapeutic agents.

\section{Materials and methods}

Reagents and cell lines. Curcumin (>80\%), Hoechst 33258, propidium iodide (PI), N-acetylcysteine (NAC), glutathione (GSH) were purchased from Sigma Chemical (St. Louis, MO, USA). Annexin V-FITC was purchased from BD Pharmingen (Minneapolis, MN, USA). Antibodies against phosphorylation JNK, p38, ERK and total JNK, p38, ERK antibodies were purchased from Santa Cruz Biotech, USA. Inhibitor specific to U0126 (ERK inhibitor), SB203580 (p38 inhibitor), and SP600125 (JNK inhibitor) were from Sigma Chemical. 5,5',6,6'-tetrachloro-1,1',3,3'-tetraethylbenzimidazolylcarbo-cyanineiodide (JC-1), 2',7'-dichlorofluorescein diacetate (DCFH-DA), were obtained from Molecular Probes (Eugene, OR, USA). Fetal bovine serum, RPMI-1640 and penicillin-streptomycin were obtained from Gibco-BRL (Gaithersburg, MD, USA). A549 human lung carcinoma cells (a gift from Dr Rong Liu, Zhejiang University) (2).

Analysis of apoptosis by Hoechst 33258 staining. Cells in the process of apoptosis show significant morphological changes in the nuclear chromatin, which can be revealed by Hoechst 33258 staining. In this assay, cells were seeded on coverslips in a 6-well plate and treated with $5-40 \mu \mathrm{M}$ curcumin. After $24 \mathrm{~h}$, the cover glasses were washed carefully with PBS and stained with $20 \mathrm{mg} / \mathrm{ml}$ Hoechst 33258 for $10 \mathrm{~min}$. Thereafter, the cells were washed in PBS and observed by a confocal fluorescence microscope.

Measurement of the change of mitochondrial membrane potential. Changes of mitochondrial membrane potential were monitored by determination of the fluorescence of the lipophilic cationic probe JC-1. Cells were treated with or without curcumin for the indicated time courses. Thirty minutes before the termination of incubation, JC-1 dye (final concentration $10 \mu \mathrm{g} / \mathrm{ml}$ ) was added to the media and incubated for $30 \mathrm{~min}$ at $37^{\circ} \mathrm{C}$ in the dark. The cells were finally harvested and washed several times with PBS. Mitochondrial membrane potential was evaluated qualitatively under a confocal microscope using $568 \mathrm{~nm}$ argon-krypton laser sources.

Measurement of ROS production. Reactive oxygen species (ROS) were reported to act as subcellular messengers in several cellular processes including apoptosis. To evaluate ROS levels, A549 cells were incubated with different concentrations of curcumin $(5,10,20$ and $40 \mu \mathrm{M})$ for $24 \mathrm{~h}$. ROS production was measured by flow cytometry. ROS production was expressed as mean fluorescence intensity (MFI), which was calculated by Cell Quest software.

Western blot analysis. Cells were lysed in a lysis buffer $(50 \mathrm{mM}$ Tris Cl, pH 7.8, $150 \mathrm{mM} \mathrm{NaCl}, 1 \%$ NP40, 0.1\% SDS, $1 \mathrm{mM}$ phenylmethylsulfonyl fluoride). The lysates were resolved on SDS-PAGE gels and then transferred to polyvinylidine difluoride membranes. Membranes were blocked in Trisbuffered solution (50 mM Tris $\mathrm{HCl}, \mathrm{pH} 7.4,150 \mathrm{mM} \mathrm{NaCl}$, $0.1 \%$ Tween-20) containing 5\% non-fat dry milk for $2 \mathrm{~h}$ at room temperature and then incubated overnight at $4{ }^{\circ} \mathrm{C}$ with specific primary antibodies, membranes were washed and incubated with horseradish peroxidase-conjugated secondary antibodies. After being washed 3-4 times, membranes were incubated with Renaissance chemiluminescence reagents. Chemiluminescent signals were imaged on X-ray film.

Statistical analysis. All data are presented as means \pm SD with $\mathrm{N}=3$ or more and independent experiments were repeated at least 3 times. Student's t-test was used to determine the significance of statistical differences between data at the level of $\mathrm{P}<0.05$.

\section{Results}

Curcumin induces apoptosis in A549 cells. To demonstrate that the cell death was due to apoptosis we examined the degree of apoptosis by PI and Annexin V staining through flow cytometric analysis (2). Results demonstrated clearly that treatment with 5-40 $\mu \mathrm{M}$ curcumin for $24 \mathrm{~h}$ increased the percentage of cells undergoing apoptosis (Annexin V+/PI-) and decreased the percentage of viable cells (Annexin V-/PI-) in a dose-dependent manner (Fig. 1A). In addition, we also observed the morphological changes of the cells treated with curcumin by Hoechst 33258 staining. In the untreated group, the nuclei were stained a less bright blue and the color was homogeneous (Fig. 1B). After the cells were treated with $20 \mu \mathrm{M}$ curcumin for $24 \mathrm{~h}$, the blue emission light in apoptotic cells was much brighter than that in the control cells. Condensed chromatin and nuclear shrinkage could also be found in curcumin-treated cells and some of them formed the structure of apoptotic bodies which is one of the classic characteristics of apoptotic cells (Fig. 1C). Based on the above identification, it showed that the mode of curcumin-induced cell death is predominantly an apoptotic reaction. 

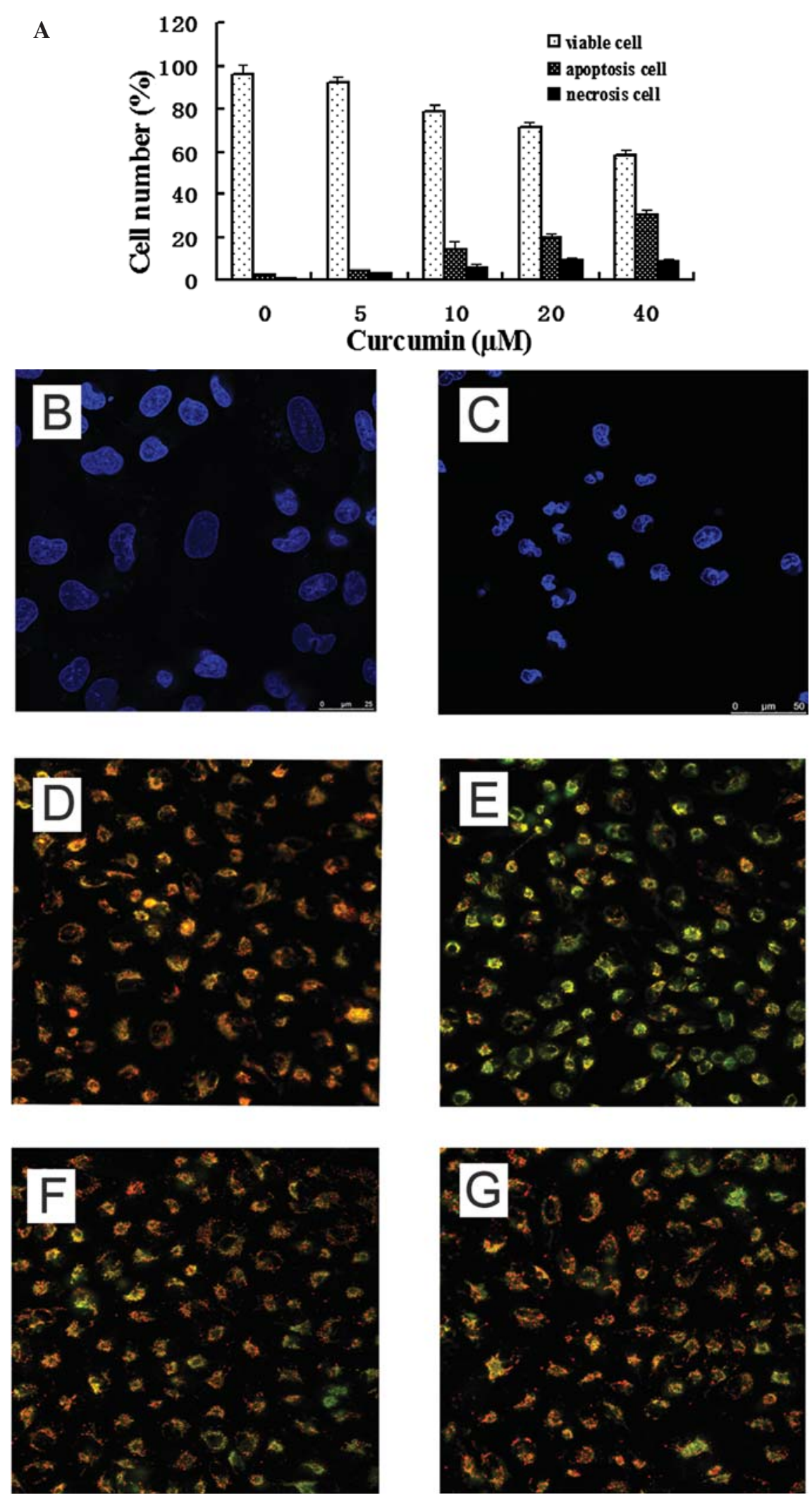

Figure 1. The chart describes the percentage of apoptotic, viable and necrotic cells (A) after treatment with different concentrations of curcumin (5-40 $\mu \mathrm{M})$ for 24 $\mathrm{h}$. Induction of apoptosis by curcumin. Cells exposed to $20 \mu \mathrm{M}$ curcumin for $24 \mathrm{~h}$ were stained with Hoechst (B and C) and FITC-conjugated Annexin-Vstained cells and quantified by flow cytometry analysis. Cells were treated with curcumin in the presence or absence of antioxidants, including NAC and GSH. Then, cells were stained with $10 \mu \mathrm{g} / \mathrm{ml}$ of JC-1 and observed under confocal microscope. (D) Control cells. (E) Curcumin (20 $\mu \mathrm{M}$ ) only. (F) NAC plus curcumin. (G) GSH plus curcumin.

Effects of curcumin on mitochondrial membrane potential. To explore the role of mitochondria in curcumin-induced cell death, cells were exposed to 5-40 $\mu \mathrm{M}$ curcumin for $24 \mathrm{~h}$ and mitochondrial membrane potential (MMP) was measured by staining mitochondria with JC-1 under a confocal fluorescence microscope. Control cells showed heterogeneous staining of 

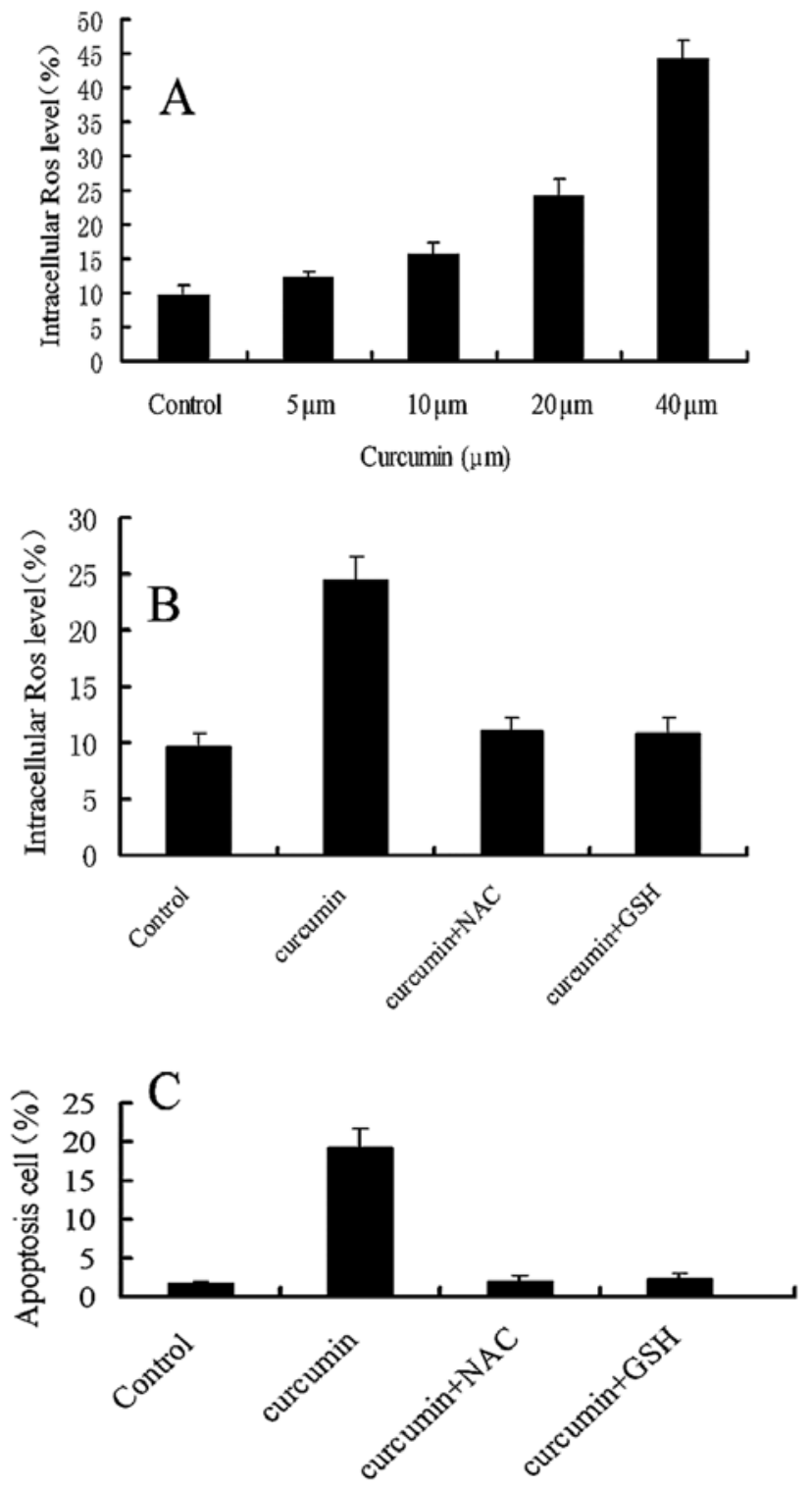

Figure 2. Effect of curcumin on reactive oxygen species (ROS) generation. Cells were treated with curcumin $(5-40 \mu \mathrm{M})$ for $24 \mathrm{~h}$ and the DCF fluorescence intensity was measured by a flow cytometry. Data in (A) are representative results from three independent experiments. (B) Effect of antioxidants on curcumin-induced ROS generation. Cells were treated with $20 \mu \mathrm{M}$ curcumin for $24 \mathrm{~h}$ in the presence or absence of $10 \mathrm{mM} \mathrm{NAC}$ and $15 \mathrm{mM} \mathrm{GSH}$. Data are mean $\pm \mathrm{SD}$ of three independent experiments performed induplicate. (C) Effect of antioxidants on curcumin-induced cell death. Cells were treated with $20 \mu \mathrm{M}$ curcumin for $24 \mathrm{~h}$ in the presence or absence of NAC and GSH. Cell apoptosis were quantified by flow cytometry analysis.

the cytoplasm with both red and green fluorescence coexisting in the same cell (Fig. 1D). Consistent with a mitochondrial localization, the red fluorescence was mostly found in rodshaped and granular structures distributed throughout the cytoplasm. Although a minority of the mitochondria exhibited only green fluorescence; these were most conspicuous in areas of cytoplasm surrounding the nucleus. Exposure of A549 cells to curcumin induced marked changes in MMP as evident from the disappearance of red fluorescence or the increase of green fluorescence in most cells, with a predominantly peripheral distribution. Some cells were devoid of red fluorescence, which is an indication of the loss of MMP and the severity of cell damage (Fig. 1E). These data suggest that curcumin induces loss of mitochondrial membrane potential. Interestingly, pretreatment of GSH or NAC prevented the changes in MMP and morphological features as similarly demonstrated in control cells (Fig. 1F and G). Hence, the present results suggest a requirement for ROS generation in curcumin-mediated loss of mitochondrial membrane potential.

Effects of curcumin on the levels of intracellular ROS. It is known that regulated changes in intracellular ROS levels can induce biochemical signaling processes that control basic cellular functions, such as proliferation and apoptosis which are prevalent in the development of cancer. Thus, to understand the possible mechanisms by which curcumin induced apoptosis in A549 lung cancer cells, the cells were exposed to 5-40 $\mu \mathrm{M}$ curcumin and changes in DCF fluorescence were detected. The flow cytometric analysis showed that the proportion of cells with higher fluorescence intensity was increased in cells exposed to curcumin for $24 \mathrm{~h}$ (Fig. 2A), indicating that curcumin significantly increased the level of ROS in A549 lung cancer cells in a dose-dependent manner. To further determine whether the level of intracellular ROS was associated with curcumin-induced cell apoptosis, cells were treated with $20 \mu \mathrm{M}$ curcumin for $24 \mathrm{~h}$ in the presence or absence of anti-oxidants, including $10 \mathrm{mM}$ NAC and $15 \mathrm{mM}$ GSH. Pretreatment of cells with the putative anti-oxidants NAC and GSH resulted in decreasing of ROS production, which did not differ from that of the DMSO control (Fig. 2B). Moreover, NAC and GSH also prevented curcumin-induced cell apoptosis (Figs. 2C and 3A-D).

Roles of MAPK signaling in curcumin-induced cell death. To investigate whether MAPK signaling pathway was involved in the curcumin-induced cell death, MAPK activation was evaluated by detecting phosphorylation of MAPK subfamilies. Cells were exposed to 5-40 $\mu \mathrm{M}$ curcumin for $24 \mathrm{~h}$ and activation of ERK, p38, and JNK was determined by Western blot analysis. As shown in Fig. 4, curcumin induced a sustained activation of ERK, JNK and p38, with little change in total ERK, p38, and JNK protein in A549 cells. To determine whether these kinases were essential for curcumin-induced cell apoptosis, the effects of MAPK inhibitors on the cell death and MAPK activation were examined. Cells were preincubated for $1 \mathrm{~h}$ with U0126, SB203580 and SP600125. Thereafter, the cells were exposed to $20 \mu \mathrm{M}$ curcumin for $24 \mathrm{~h}$. We found that $\mathrm{p} 38$ phosphorylation was reduced in cells pretreated for $1 \mathrm{~h}$ with $20 \mu \mathrm{M}$ of the p38 inhibitor SB203580. Similarly, ERK and JNK phosphorylation was also reduced in cells pretreated with $20 \mu \mathrm{M}$ U0126 and $20 \mu \mathrm{M}$ SP600125 (Fig. 5). However, pretreatment with SB203580, U0126 or SP600125 in curcumin-treated cells failed to reduce the number of apoptotic cells (data no shown). Taken together, these results demonstrate that curcumin promotes the activation of $\mathrm{p} 38$, JNK and ERK, but that these events are not necessary for the execution of apoptosis.

\section{Discussion}

The present study demonstrated that curcumin remarkably induced lung cancer A549 cell apoptosis, which could be 

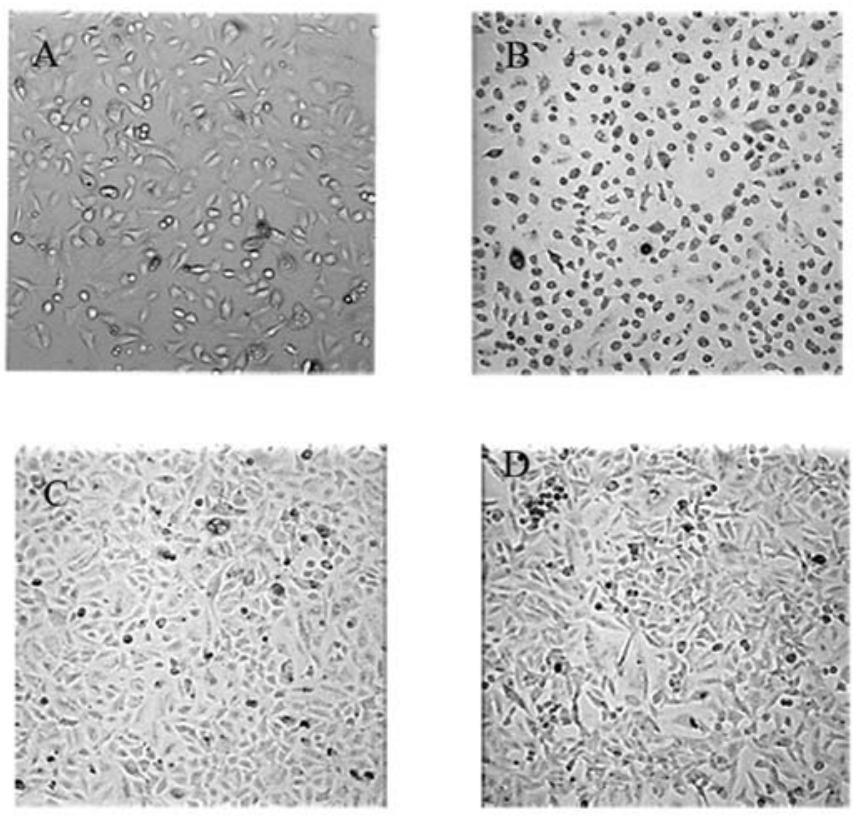

Figure 3. Cell morphological changes were estimated by light microscope (A) Control cells. (B) Curcumin (20 $\mu \mathrm{M})$ only. (C) NAC plus curcumin. (D) GSH plus curcumin.

\section{control $5 \mu \mathrm{M} 10 \mu \mathrm{M} 20 \mu \mathrm{M} 40 \mu \mathrm{M}$}

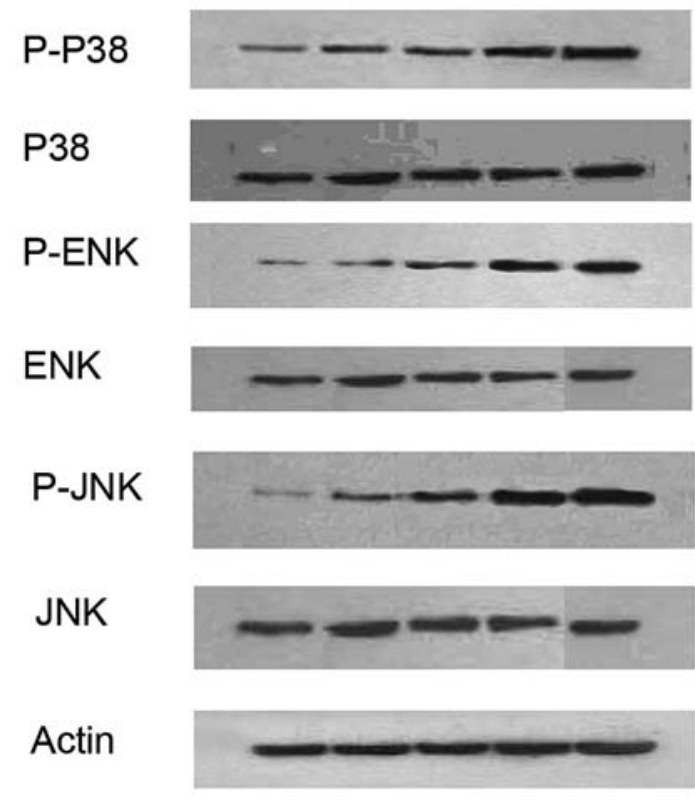

Figure 4. Curcumin up-regulated the activation of MAPK phosphorylation in A549 lung cancer cell lines. Cells were incubated in the absence or presence of curcumin $(5-40 \mu \mathrm{M})$ for the indicated time courses. Then, the cells were harvested and lysed for the detection expressions of ERK, p38 and JNK phosphorylation by Western blot analysis.

confirmed by the Annexin V staining. The induction of A549 cell apoptosis by curcumin was also investigated by evaluating the apoptotic morphology of cell nuclei by Hoechst staining using fluorescence imaging. As evidence of apoptosis, the nuclei of A549 cells incubated with $20 \mu \mathrm{M}$ curcumin was smaller and with a more compacted chromatin than the nuclei of cells treated with DMSO (Fig. 1A and B). Our data correlated well with previous studies where curcumin

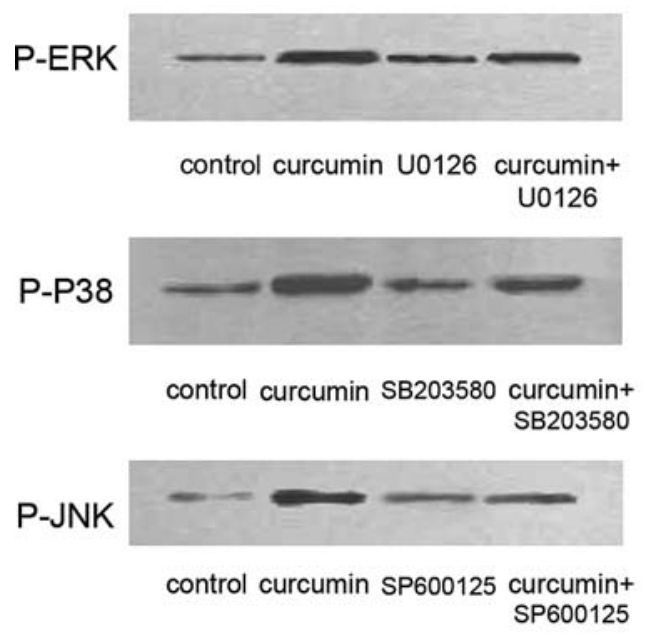

Figure 5. Effect of MAPK inhibitors on activation of MAPK. Cells were treated with $20 \mu \mathrm{M}$ curcumin for $24 \mathrm{~h}$ in the presence or absence of SB203580, U0126 or SP600125. The activation of ERK, p38, and JNK was evaluated by Western blot analysis.

induced apoptosis in many tumor cells, including AK-5 tumor cells (16), breast tumor cells (17) and lung cancer (3).

There is accumulating evidence indicating that mitochondria play a pivotal role in the apoptotic process in mammalian cells. Loss of mitochondrial membrane potential (MMP) is considered to be an indicator of mitochondria damage and generally is defined as an early stage of apoptosis, preceding efflux of small molecules from the mitochondria (including cytochrome c, apoptosis-inducing factor, and cIAPs) and followed by caspase- $9 /$ caspase -3 cascade activation (18). In this study, we proceeded to determine curcumin's effect on mitochondrial membrane potential using a mitochondrial-specific cationic dye JC-1 to confirm the loss of MMP by curcumin exposure. The results showed that curcumin induced loss of mitochondrial membrane potential in a dose-dependent manner. In addition, the loss of MMP has also been reported in various types of tumor cells exposed to other putative cancer chemopreventive agents during apoptosis $(19,20)$. These would suggest that the change of mitochondrial function observed during curcumin-induced apoptosis in A549 cells was perhaps not an agent- or cell type-specific phenomenon.

Mitochondria are a major source of intracellular reactive oxygen species (ROS) production, and ROS have been implicated as second messengers and are known to participate in physiological processes, such as apoptosis and proliferation. The relationship between ROS and mitochondrial functions is not clear, although several previous studies provided both positive and negative evidence on this topic $(21,22)$. In several apoptotic models, increased generation of ROS was described as an early event; in addition, enhanced ROS formation and impairment of the cellular anti-oxidant mechanisms may also lead to cellular apoptosis (23). However, ROS are able to play a role as mitogens to induce proliferation and protect cells from apoptosis induced by oxidative stresses $(24,25)$. These data suggest a double-sided function of ROS. Here we first evaluated whether the elevation of intracellular ROS attribute to curcumin-induced apoptosis in A549 cells. Our results suggest a good relationship between the generation of ROS 
and the induction of apoptosis in tumor cells. To further examine the role of ROS in curcumin-induced apoptosis, the effects of anti-oxidants on the action of curcumin was first examined. Among various anti-oxidants, GSH and NAC are used as synthetic compounds treated with curcumin. NAC is a precursor of GSH, which is a ubiquitous tripeptide composed of glutamate, cysteine and glycine. GSH neutralizes and scavenges oxygen and other free radical species. GSH reacts with hydrogen peroxide to produce water by glutathione peroxidases and protects the cells against oxidative damage. In our results, GSH and NAC had similar protective effects on curcumin-induced cell apoptosis and ROS formation. Interestingly, these anti-oxidants completely reduced the loss of MMP and prevented cell apoptosis in curcumin-treated cells. These results suggested that the elevation of intracellular ROS attribute to curcumin-induced apoptosis in A549 cells. The curcumin-mediated loss of MMP and apoptosis in A549 cells is apparently dependent on ROS generation. Our results are in accordance with a previous study showing that increased level of inherent ROS could be determinants in tumor cell apoptotic susceptibility to curcumin $(6,7,26)$.

MAPK pathways play an important role in signal transduction from the cell surface to the nucleus in response to a wide variety of extracellular signals and the activation of these pathways may activate gene transcription. ERK is generally activated by mitogenic and proliferative stimuli and involved in cellular proliferation and differentiation. JNK and p38 kinase are mainly activated by extracellular stresses (27-29). Activation of these kinases causes variable cellular responses depending upon cell type. Some studies have shown that curcumin represses or promotes ERK, JNK and p38 activation, while others have found no effect of curcumin on ERK, JNK and p38 activation (13-15,30-32). These findings indicated a dual role for MAPK in the cellular response that appeared to be specific to the type of cell and apoptotic stimulus studied. The exact role of MAPK activity in apoptosis remained to be elucidated. In the present study, we found that after incubation with curcumin for $24 \mathrm{~h}$, the phosphorylated ERK, JNK and p38 content had an obvious increase in dose-dependent manner. However, pretreatment with SB203580, U0126 or SP600125 in curcumin-treated cells failed to reduce the number of apoptotic cells. Some studies have shown that ROS can regulate the activity of MAPK pathways that may be involved in cellular responses including proliferation, differentiation and apoptosis $(14,15)$. Our results suggested that the induction of p38, JNK and ERK were part of the cellular response to curcumin, but that the activation of $\mathrm{p} 38$, JNK and ERK were not a primary pathway in the induction of apoptosis of A549 cells by curcumin.

In conclusion, our results support the notion that ROS play a critical role in curcumin-induced apoptosis in A549 cells. Firstly, a dose-dependent increase in intracellular ROS level was observed concomitantly with the apoptotic changes in A549 lung cancer cells after curcumin treatment. Secondly, NAC and GSH plus curcumin, which prevented the dysfunction of mitochondria, effectively suppressed the increase in ROS format and subsequently cell death. Thirdly, curcumin promoted the activation of $\mathrm{p} 38$, JNK and ERK. However, pretreatment with MAPK inhibitors in curcumin-treated cells failed to reduce the number of apoptotic cells. Numerous investigations have indicated the involvement of ROS in apoptosis induced by various stimuli. Nevertheless, the exact mechanism by which ROS causes apoptosis in curcumintreated A549 cells remains to be further elucidated.

\section{Acknowledgements}

This project supported by the Zhejiang Traditional Chinese Medicine Administration Bureau (Project: No. 2008CA077) and the Funds of the Nanjing Command Health Speciality '122' Engineering (Funds: No. 342510001). We would like to thank Drs Yakun Ge and Lisheng Qian for their technical assistance and discussion.

\section{References}

1. Antosiewicz J, Ziolkowski W, Kar S, Powolny AA and Singh SV: Role of reactive oxygen intermediates in cellular responses to dietary cancer chemopreventive agents. Planta Med 74: 1570-1579, 2008.

2. Chen QY, Wu LJ, Wu YQ, Lu GH, Zhan JW, Jiang ZY, Yan J and Zhou JY: Molecular mechanism of trifluoperazine induces apoptosis in human A549 lung adenocarcinoma cell lines. Mol Med Rep 2: 811-817, 2009.

3. Zhang J, Qi HW and Wu CG: Research of anti-proliferation of curcumin on A549 human lung cancer cells and its mechanism. Zhong Yao Cai 27: 923-927, 2004.

4. Tian DZ, Zhu H and Liang YJ: Effects and mechanisms of curcuminon apoptosis of lung adenocarcinoma A549 cells. Chin J Clin Pharmacol 15: 8-10, 2006.

5. Mishra S, Kapoor N, Mubarak Ali A, Pardhasaradhi BV, Kumari AL, Khar A and Misra K: Differential apoptotic and redox regulatory activities of curcumin and its derivatives. Free Radic Biol Med 38: 1353-1360, 2005.

6. Skommer J, Wlodkowic D and Pelkonen J: Cellular foundation of curcumin induced apoptosis in follicular lymphoma cell lines. Exp Hematol 34: 463-474, 2006.

7. Cao J, Jia L, Zhou HM, Liu Y and Zhong LF: Mitochondrial and nuclear DNA damage induced by curcumin in human hepatoma G2 cells. Toxicol Sci 91: 476-483, 2006.

8. Atsumi T, Tonosaki $\mathrm{K}$ and Fujisawa $\mathrm{S}$ : Comparative cytotoxicity and ROS generation by curcumin and tetrahydrocurcumin following visible-light irradiation or treatment with horseradish peroxidase. Anticancer Res 27: 363-371, 2007.

9. Chan WH, Wu HJ and Hsuuw YD: Curcumin inhibits ROS formation and apoptosis in methylglyoxal-treated human hepatoma G2 cells. Ann NY Acad Sci 1042: 372-378, 2005.

10. Kim YS, Jhon DY and Lee KY: Involvement of ROS and JNK1 in selenite-induced apoptosis in Chang liver cells. Exp Mol Med 36: 157-164, 2004.

11. Sano M, Fukuda K, Sato T, Kawaguchi H, Suematsu M, Matsuda S, Koyasu S, Matsui H, Yamauchi-Takihara K, Harada M, Saito Y and Ogawa S: ERK and p38 MAPK, but not NF-kappaB, are critically involved in reactive oxygen speciesmediated induction of IL-6 by angiotensin II in cardiac fibroblasts. Circ Res 89: 661-669, 2001.

12. Jang JH and Surh YJ: Beta-amyloid induces oxidative DNA damage and cell death through activation of c-Jun $\mathrm{N}$ terminal kinase. Ann NY Acad Sci 973: 228-236, 2002.

13. Chen YC, Tsai SH, Shen SC, Lin JK and Lee WR: Alternative activation of extracellular signal-regulated protein kinases in curcumin and arsenite-induced HSP70 gene expression in human colorectal carcinoma cells. Eur J Cell Biol 80: 213-221, 2001 .

14. Aoki H, Takada Y, Kondo S, Sawaya R, Aggarwal BB and Kondo Y: Evidence that curcumin suppresses the growth of malignant gliomas in vitro and in vivo through induction of autophagy: role of Akt and extracellular signal-regulated kinase signaling pathways. Mol Pharmacol 72: 29-39, 2007.

15. Collett GP and Campbell FC: Curcumin induces c-jun N-terminal kinase-dependent apoptosis in HCT116 human colon cancer cells. Carcinogenesis 25: 2183-2189, 2004.

16. Khar A, Ali AM, Pardhasaradhi BV, Begum Z and Anjum R: Antitumor activity of curcumin is mediated through the induction of apoptosis in AK-5 tumor cells. FEBS Lett 445: 165-168, 1999. 
17. Ramachandran C and You W: Differential sensitivity of human mammary epithelial and breast carcinoma cell lines to curcumin. Breast Cancer Res Treat 54: 269-278, 1999.

18. Green DR and Reed JC: Mitochondria and apoptosis. Science 281: 1309-1312, 1998.

19. Nakamura Y, Kawakami M, Yoshihiro A, Miyoshi N, Ohigashi H, KawaiK, Osawa T and Uchida K: Involvement of the mitochondrial death pathway in chemopreventive benzyl isothiocyanate-induced apoptosis. J Biol Chem 277: 8492-8499, 2002.

20. Gamet-Payrastre L, Li P, Lumeau S, Cassar G, Dupont MA Chevolleau S, Gasc N, Tulliez J and Tercé F: Sulforaphane, a naturally occurring isothiocyanate, induces cell cycle arrest and apoptosis in HT29 human colon cancer cells. Cancer Res 60: 1426-1433, 2000.

21. O'Rourke TW, Doudican NA, Mackereth MD, Doetsch PW and Shadel GS: Mitochondrial dysfunction due to oxidative mitochondrial DNA damage is reduced through cooperative actions of diverse proteins. Mol Cell Biol 22: 4086-4093, 2002.

22. Cai Z, Lin M, Wuchter C, Ruppert V, Drken B, Ludwig WD and Karawajew L: Apoptotic response to homoharringtonine in human wt p53 leukemic cells is independent of reactive oxygen species generation and implicates Bax translocation, mitochondrial cytochrome c release and caspase activation. Leukemia 15: 567-574, 2001

23. Zamzami N, Marchetti P, Castedo M, Decaudin D, Macho A Hirsch T, Susin SA, Petit PX, Mignotte B and Kroemer G: Sequential reduction of mitochondrial transmembrane potential and generation of reactive oxygen species in early programmed cell death. J Exp Med 182: 367-377, 1995.

24. Kops GJ, Dansen TB, Polderman PE, Saarloos I, Wirtz KW, Coffer PJ, Huang TT, Bos JL, Medema RH and Burgering BM: Forkhead transcription factor FOXO3a protects quiescent cells from oxidative stress. Nature 419: 316-321, 2002.
25. Kim BY, Han MJ and Chung AS: Effects of reactive oxygen species on proliferation of Chinese hamster lung fibroblast (V79) cells. Free Radic Biol Med 30: 686-698, 2001.

26. Liao YF, Hung HC, Hour TC, Hsu PC, Kao MC, Tsay GJ and Liu GY: Curcumin induces apoptosis through an ornithine decarboxylase-dependent pathway in human promyelocytic leukemia HL-60 cells. Life Sci 82: 367-375, 2008.

27. Kyriakis JM and Avruch J: Mammalian mitogen-activated protein kinase signal transduction pathways activated by stress and inflammation. Physiol Rev 81: 807-869, 2001.

28. Chung HS, Park SR, Choi EK, Park HJ, Griffin RJ, Song CW and Park H: Role of sphingomyelin-MAPKs pathway in heatinduced apoptosis. Exp Mol Med 35: 181-188, 2003.

29. Kang SH, Song JH, Kang HK, Kang JH, Kim SJ, Kang HW, Lee YK and Park DB: Arsenic trioxide-induced apoptosis is independent of stress-responsive signaling pathways but sensitive to inhibition of inducible nitric oxide synthase in HepG2 cells. Exp Mol Med 35: 83-90, 2003.

30. Woo MS, Jung SH, Kim SY, Hyun JW, Ko KH, Kim WK and Kim HS: Curcumin suppresses phorbol ester-induced matrix metalloproteinase- 9 expression by inhibiting the PKC to MAPK signaling pathways in human astroglioma cells. Biochem Biophys Res Commun 335: 1017-1025, 2005.

31. Chen YR and Tan TH: Inhibition of the c-Jun N-terminal kinase (JNK) signaling pathway by curcumin. Oncogene 17: 173-178, 1998.

32. Choi BH, Kim CG, Bae YS, Young-Seuk B, Yoongho L, Young HL and Soon YS: p21 Waf1/Cip1 expression by curcumin in U-87MG human glioma cells: role of early growth response-1 expression. Cancer Res 68: 1369-1377, 2008. 